\title{
TINJAUAN KONDISI DAERAH IRIGASI MAKOTYAMSA KABUPATEN SORONG
}

\author{
Della Natasya Putri ${ }^{1)}$ Muhammad Ramadhan ${ }^{2)}$ Hendrik Pristianto $^{3)}$ \\ ${ }^{112) 3)}$ Program Studi Teknik Sipil Universitas Muhammadiyah Sorong \\ J1. Pendidikan No 27 Kota Sorong \\ Email: dellanatasyap56@gmail.com
}

\begin{abstract}
Abstrak
Makotyamsa merupakan salah satu desa yang terletak di Kecamatan Mayamuk kabupaten Sorong. Dengan kondisi wilayah yang gersang dan mempunyai drainase yang kering membuat terbatasnya ketersediaan air permukaan dan berdasarkan survei yang dilakukan menyatakan sulitnya mendapatkan air sehingga petaniannya mengandalkan air hujan, maka diupayakan dengan memanfaatkan air tanah dengan cara membuat sumur pompa, dimana potensi lahan pertanian cukup besar. Tujuan dari penelitian ini adalah untuk menanggulangi masalah yang terjadi di persawahan Kabupaten Sorong yang sering terjadi gagal panen karena kekurangan sumber daya air. Kebutuhan air tanaman tiap masa tanam terjadi penurunan akibat stress kekurangan air di daerah perakaran sehingga menyebabkan pula menurunnya hasil produksi pada lahan kondisi tadah hujan. Hal ini menunjukkan bahwa tingkat deplesi lengas tanah selama periode tanam sangat besar sehingga jumlah air yang dibutuhkan untuk mengisi daerah perakaran pun semakin besar.
\end{abstract}

Kata Kunci : Kebutuhan air tanaman, Persawahan, Kabupaten Sorong 


\section{PENDAHULUAN}

Irigasi adalah usaha penyediaan, pengaturan, dan pembuangan air irigasi untuk menunjang pertanian dan kebutuhan manusia, yang berfungsi untuk mengaliri lahan dan menampung air di saat hujan dan mengalirkan air pada saat kemarau agar persediaan air tetap tersedia.

Sering pemberian air pada petakan irigasi terjadi kelebihan yang menyebabkan banyaknya air yang terbuang sehingga air tidek efisiens di lapangan. Oleh karena itu perlu manajemen irigasi untuk memanage system pemberian air irigasi yang lebih efisien, Dalam hal ini air yang disalurkan ke lahan harus tepat waktu dan jumlah dengan yang dibutuhkan di lahan.

Untuk mengoptimalkan pemanfaatan sumber daya air sungai, maka penggunaan air dan produktivitas irigasi harus dimaksimalkan. Penerapan pola tanam (padi-padi) dan system pemberian air terus-menerus (continous flow system) ataupun dengan system terputus-putus pada petak tersier daerah irigasi. Karena itu dalam rangka peningkatan efisiensi penggunaan air irigasi, perlu dilakukan kajian terhadap hasil perencanaan system pemberian air pada petak tersier dan pola tanam.

Jenis-jenis system irigasi meliputi irigasi permukaan, irigasi rawa, irigasi air bawah tanah, irigasi pompa, irigasi tambak, dan lain-lain.

\section{METODOLOGI}

\section{Lokasi Studi}

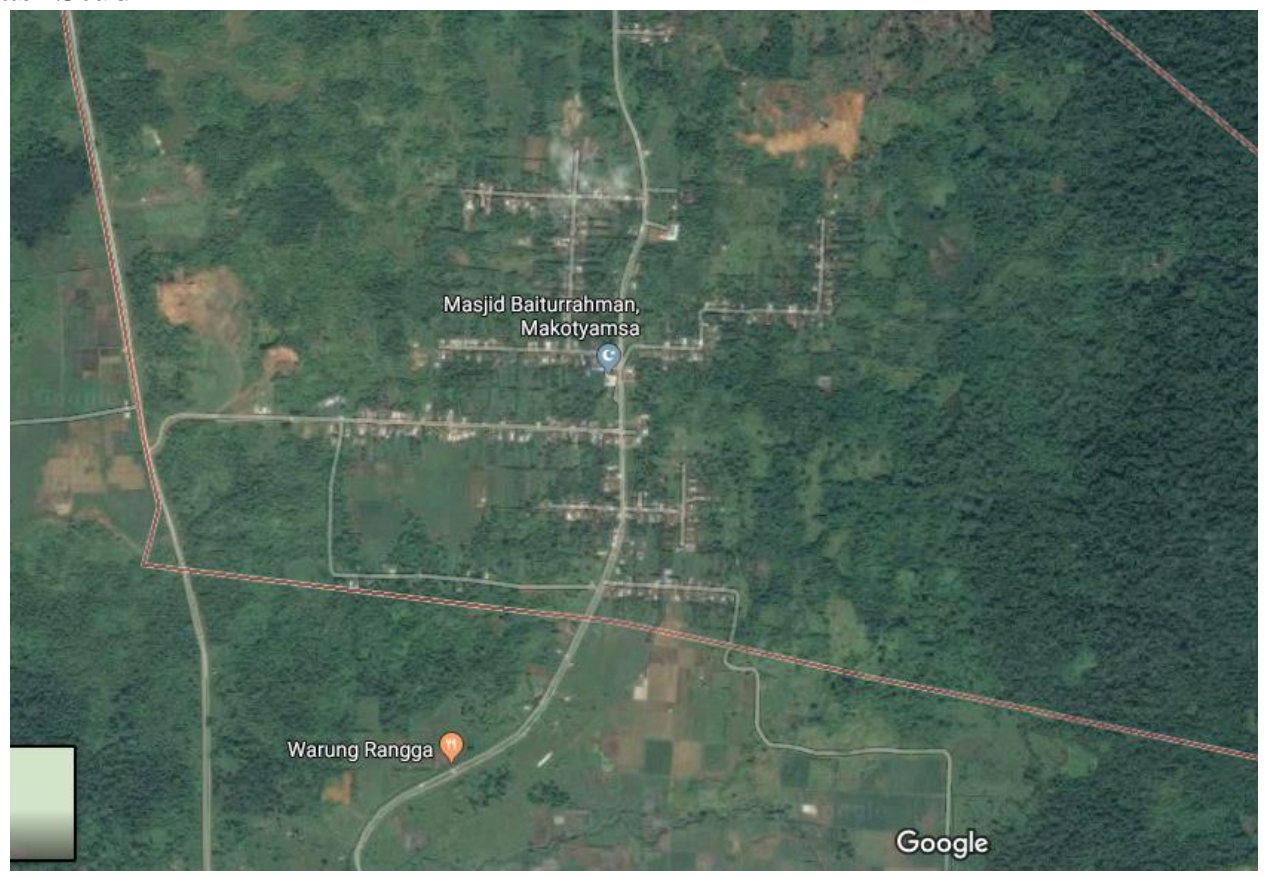

Gambar 1. Lokasi Studi

Tahapan Penyusunan Artikel :

1. Penentuan tema artikel

2. Penelusuran artikel yang bersesuaian dengan tema yang kita ambil (melalui google scholar)

3. Analisa komparatif terhadap artikel yang didapatkan dari google scholar

4. Membuat kesimpulan untuk menjawab tujuan penulisan artikel 
Semua metode penulisan dan analisa dalam artikel ilmiah ini merujuk pada panduan penulisan tugas akhir Fakultas Teknik Universitas Muhammadiyah Sorong tahun 2014. (Pristianto, Amri, \& Rusdi, 2018).

\section{HASIL DAN PEMBAHASAN}

Beberapa hasil penelitian yang diambil secara langsung adalah sebagai berikut:

a. Kondisi Wilayah Studi

1. Daearah studi terletak di Kabupaten Sorong kecamatan Mayamuk kelurahan Makotyamsa, Papua Barat padakordinat-1,0827450, 131,2947300

2. Luas wilayah daerah irigasi $12 \mathrm{Ha}$

3. Akses bias melalui darat ke 3 bendungan untuk pemasok daerah irigasi.

b. Kondisi Daerah Irigasi

1. Luas areal persawahan : $12 \mathrm{Ha}$

2. Sumber air dari 3 bendungan

Gambar diambil dari google maps tahun 2014
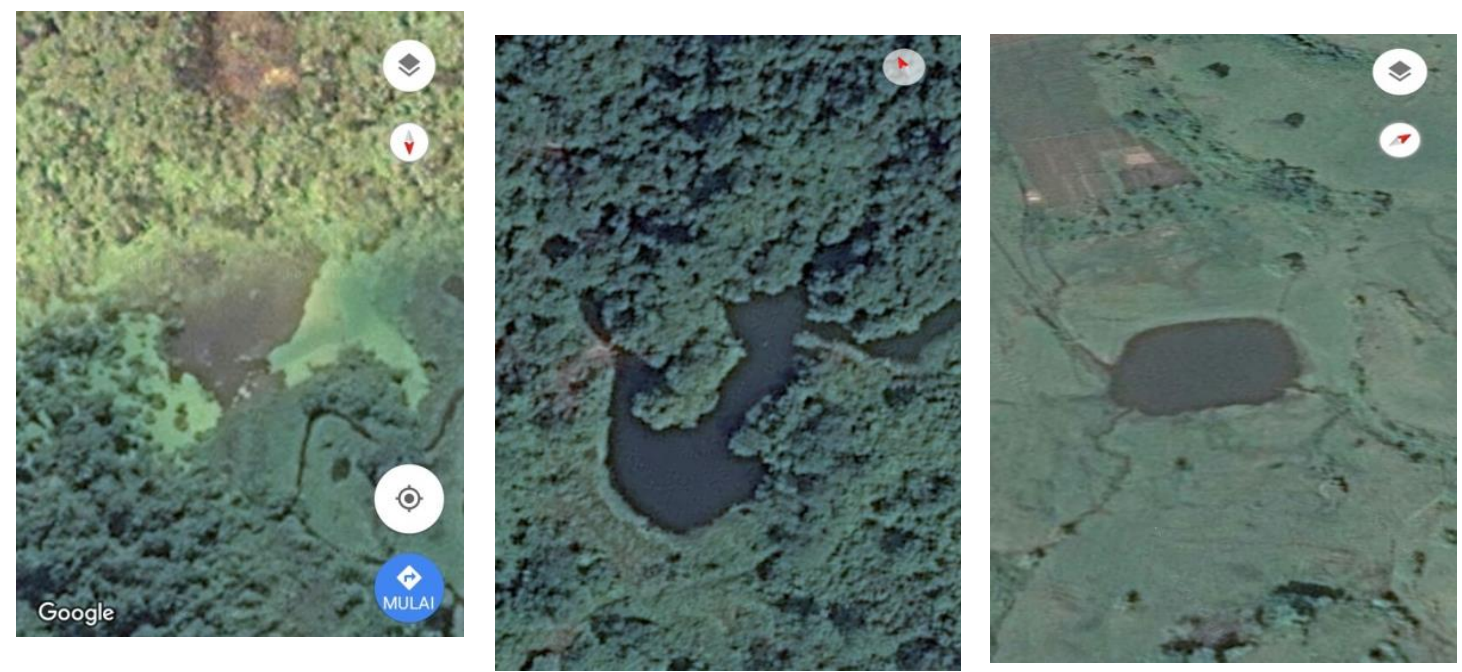

3. Pola Tata Tanam : 3 jenis dalam satu tahun diantaranya: Padi, Cabai dan Tomat

4. Hasil panen : Cabai, Tomat, Padi, Semangka dan Jagung,

5. Kendala ditemui terkait pemenuhan kebutuhan irigasi

- Penyaluran irigasi ke daerah persawahan masih belum ada

- Para petani masih berusaha untuk memenuhi kebutuhan air sawahnya dengan mandiri melalui aliran sungai.

- Masih banyak para petani yang bergantung terhadap air hujan.

- Banyak petani yang beralih dari padi karena modal dari pada hasil berbanding terbalik. Dimana modal yang dibutuhkan sangat besar.

Sistem drainase disana juga sangat buruk, karena disana persawahannya sering banjir yang mengakibatkan gagal panen. Karena salah satu penyebabnya adalah tanaman para tani tidak bisa terendam kurang lebih 4 jam. 


\section{Analisa}

Kondisi daerah irigasi Makotyamsa dapat diuraikan sebagai berikut :

1. Dibutuhkan peran pemerintah langsung terhadap para tani umtuk membangun saluran-saluran irigasi ke area persawahan.

2. Perbaikan system drainase harus segera dilakukan untuk mendorong hasil tani ke arah yang lebih baik lagi.

3. Para tani menginginkan bantuan berupa bukti nyata seperti barang dibandingkan uang tunai. Karena bantuan berupa uang tidak pernah sampai di petani.

\section{KESIMPULAN}

Permasalahan utama sistem irigasi di Kabupaten Sorong adalah para tani yang mendapatkan haknya berupa bantuan dari pemerintah belum sepenuhnya terlaksana sehingga tani berinisiatif daerah persawahan hanya dapat dilakukan penyaluran irigasi melalui aliran sungai maupun air hujan.

\section{DAFTAR PUSTAKA}

1. Ramadhan et al., (2016). Analisis Kebutuhan Tani Membangun Saluran Irigasi (Studi Kasus Kabupaten Sorong).

2. Karnaen, Z., Purnama, A., \& Amin, I. (2018). Perencanaan Jaringan Irigasi Air Tanah Di Desa Buin Baru Kecamatan Buer Kabupaten Sumbawa.

3. Pristianto, H. (2018). Aplikasi Cropwat 8.0 Sebagai Upaya Menganalisa Kebutuhan Air Irigasi Dan Hasil Produksi Tanaman Jagung Di Kelurahan Matalamagi Kota Sorong.

4. Pristianto, H., Amri, I., \& Rusdi, A. (2018). Pedoman Penulisan Tugas Akhir Fakultas Teknik Universitas Muhammadiyah Sorong. 